\title{
Developmental progression of performance on the Tower of Hanoi problem
}

\author{
MARYANN M. BYRNES \\ Boston University, Boston, Massachusetts 02215
}

and

\author{
HERMAN H. SPITZ \\ E. R. Johnstone Training and Research Center, Bordentown, New Jersey 08505
}

\begin{abstract}
Groups of children and adolescents of average intelligence, at every age from 6 to 18 years, and college students of slightly above average intelligence were presented with two-disk and three-disk versions of the Tower of Hanoi problem. Criterion was two successive solutions in the minimum number of moves. Ability to reach criterion on the two-disk problem increased to near-perfect performance at age 8. On the three-disk problem, there were two transition periods--one between 7 and 9 years of age, the other between 11 and 14 years of age. The incorrect first move was the largest source of error on the three-disk problem.
\end{abstract}

In an earlier study using the Tower of Hanoi problem, in which 6- to 11-year-old nonretarded children were compared with mildly retarded adolescents, we noted a marked increase in problem solving skill at 8 years of age (Byrnes \& Spitz, 1977). This timing corresponds to the beginning of Piaget's stage of concrete operations. Piaget (1974/1976) has reported another substantial improvement in Tower of Hanoi performance at ages 11 and 12 years, corresponding to the beginning of the stage of formal operational thinking. We had found no such transition period at age 11 years, and, consequently, the focus of the current study is further observation of Tower of Hanoi performance in adolescents, to more precisely determine developmental progression of problem solving skills.

A number of researchers have used the tower to study strategic problem solving behavior (e.g., Byrnes \& Spitz, 1977; Cook, 1937; Ewert \& Lambert, 1932; Gagné \& Smith, 1962; Klahr, 1978, Note 1; Piaget, 1974/1976; Simon, 1975). Among the tower's assets for such study are its nonverbal nature and the fact that, by adding disks, it can be made increasingly more difficult unless the subject discovers a solution principle that is applicable to any number of disks. In addition, starting and/or goal configurations can be set at any state in the

This study was supported in part by Grant HD 07329 from the National Institute of Child Health and Human Development. The authors are most grateful to Joseph Anghelone, Peter Buerman, Vic Combs, Harold Cox, Stephanie Craib, Richard Dougherty, Margaret Martin, Robert McFrye, Mary Murphy, Norma Nachtsheim, Edgar Thomas, and Jan Wallender for providing space and arranging for student participation, to Martin Groff for his aid in compiling the material for this study, and to Suzanne Borys for statistical assistance. Requests for reprints should be sent to Herman H. Spitz, E. R. Johnstone Training and Research Center, Bordentown, New Jersey 08505. legal progression, and recording the subject's disk placements provides an imprint of the course of problem solution and a record of types of errors.

We used a Tower of Hanoi puzzle consisting of three vertical pegs set in a straight line. Upon one of the pegs were either two or three disks, ordered in decreasing size from bottom to top. The subject's task was to move the tower from its original peg (home) to a specified goal peg. Two rules were to be observed: Only one disk could be moved at a time, and a larger disk was never to be placed over a smaller one. All three pegs could be used in transferring disks. The minimum number of moves required to solve the problem can be derived from the formula $2^{n}-1$, where $n$ is the number of disks.

\section{METHOD}

\section{Subjects}

Characteristics of the subjects are presented in Table 1. Groups 6-10 and half of Group 11 were from a previous study, in which methods for choosing "average" subjects were detailed (Byrnes \& Spitz, 1977). Subjects were from lower middle and middle class socioeconomic backgrounds.

There were IQ scores available for Groups 12 and older, and students were included if their scores fell between 90 and 110 . For half of Groups 11 and 14 and all of Groups 12 and 13, these scores were obtained from the Short Form Test of Academic Aptitude. The remaining public school students were tested with the Otis-Lennon Mental Abilities Test. College students were volunteers from an introductory education course on mainstreaming handicapped children, and their IQs were measured with the Slosson Intelligence Test. No selection for IQ was made for this group. Groups were approximately evenly distributed as to sex in the younger groups, but with a slight preponderance of females in Groups 13 and up.

\section{Apparatus and Procedure}

Because apparatus and procedure were the same as in the previous study (Byrnes \& Spitz, 1977), only a summary description of the procedure will be given here. Four separate tasks 
Table 1

Characteristics of the Subjects

\begin{tabular}{lrrrrrr} 
& & \multicolumn{2}{c}{ Age } & & \multicolumn{2}{c}{ IQ* $^{*}$} \\
\cline { 6 - 7 } Group & $\mathrm{N}$ & Mean & SD & & Mean & SD \\
\hline 6 & 15 & 5.88 & .21 & & \\
7 & 15 & 6.88 & .31 & & \\
8 & 15 & 7.96 & .21 & & \\
9 & 15 & 9.00 & .32 & & \\
10 & 15 & 10.04 & .35 & & \\
11 & 30 & 10.90 & .28 & & \\
12 & 15 & 11.96 & .33 & 103 & 5 \\
13 & 15 & 12.92 & .24 & 104 & 4 \\
14 & 30 & 14.25 & .22 & 102 & 7 \\
15 & 15 & 14.92 & .36 & 98 & 6 \\
16 & 15 & 16.17 & .27 & 102 & 7 \\
17 & 15 & 16.90 & .17 & 101 & 8 \\
18 & 10 & 17.90 & .17 & 98 & 4 \\
College & 15 & 20.70 & .59 & 115 & 15 \\
\hline
\end{tabular}

*Data not available for first six groups.

were given in the following order: Task 1 required transfer of the two-disk tower from one end (home) peg to the other end (goal) peg. Task 2 required transfer of the two-disk tower from the center peg to the goal peg. Tasks 3 and 4 required the same transfers, but using the three-disk tower. For Tasks 1 and 3, approximately half the subjects of each sex started on Peg 1, half on Peg 3. Once a goal peg was designated for a subject, it remained constant for that subject through all four tasks.

Criterion was two consecutive transfers in the minimum number of moves. Violation of a rule was brought to the subject's attention at the end of the trial, which was considered a failed trial, and the subject was then encouraged to adhere to the rules. Subjects who obeyed all rules but transferred the tower in more than the minimum number of moves were praised and encouraged to perform the transfer in fewer moves. A score of 5 was given if criterion was reached on the second trial of a task, a score of 4 if criterion was reached on the third trial, and so on, to a score of 1 for reaching criterion on the sixth trial.

\section{RESULTS AND DISCUSSION}

Since there were no appreciable differences between Tasks 1 and 2, or between Tasks 3 and 4 , the former were combined into a single two-disk score, and the latter, into a single three-disk score.

Data analysis and figure presentation includes the results from the younger groups (Byrnes \& Spitz, 1977) in order to provide continuity across the entire age spectrum. Figure 1 shows a single transition period between ages 7 and 8 years on the two-disk tower, and two transition periods, the first between ages 7 and 9 years, the second between ages 11 and 14 years, on the three-disk tower.

Because the score distributions' extreme deviation could not be normalized by transforms, results were analyzed by the nonparametric Kruskal-Wallis one-way analysis by ranks, corrected for ties. A significant difference was found across the groups on the two-disk problem $[\mathrm{H}(13)=83.26, \mathrm{p}<.001]$ and on the threedisk problem $[H(13)=82.29, \mathrm{p}<.001]$. The large sample approximation of the Mann-Whitney U test, which yielded a $\mathrm{z}$ score that incorporated a correction for ties, was used to test the significance of increments in performance. To control for the number of comparisons being made, Ryan's method of adjusted significance levels (two-tailed) was used (Kirk, 1968). On the twodisk problem the difference between ages 7 and 8 years was reliable $[\mathrm{z}(15,15)=3.52, \mathrm{p}<.01]$. On the threedisk problem, differences between ages 7 and 9 years $[\mathrm{z}(15,15)=3.22, \mathrm{p}<.05]$, as well as between ages 11 and 14 years $[\mathrm{z}(30,30)=3.34, \mathrm{p}<.05]$, were reliable.

Of those subjects who failed to reach criterion on Task 3, 6- and 7-year-olds, having made the wrong initial move (moved the smallest disk to the storage rather than to the goal peg), simply violated game rules or gave up and started over again, continuing to make the same error. About half the 8- to 13-year-olds and all the subjects 14 years and over who failed to reach criterion finally did transfer the tower, albeit in excess moves. Their failure to reach criterion resulted almost exclusively from the incorrect initial move. It should be noted that the required first step of moving the smallest disk to the goal peg temporarily blocks the very peg to which the two larger disks must be transferred. To make this initial move requires that an untenable position be accepted temporarily with the realization that such a state is reversible and necessary for the long-term objective.

Klahr (Note 1), using a variant of the tower problem, required preschool children to describe the sequence of moves necessary to solve a series of problems of gradually increasing difficulty. He used a strict criterion of four consecutive errorless trials at each step. His (presumably bright) 5-year-old group performed perfectly at Problem Length 4 but showed a sharp drop in performance level at Problem Length 5, equivalent to our problem after two moves have put the smallest disk on the goal peg and the medium disk on the storage peg. Nevertheless, roughly one-third of this group passed this problem and even reached criterion on the six-step problem, which is equivalent to our problem with the initial move already made. However, almost none reached criterion on the full seven-step problem. There is consensus, then, that the initial move of the seven-step problem is a major stumbling block, and some evidence

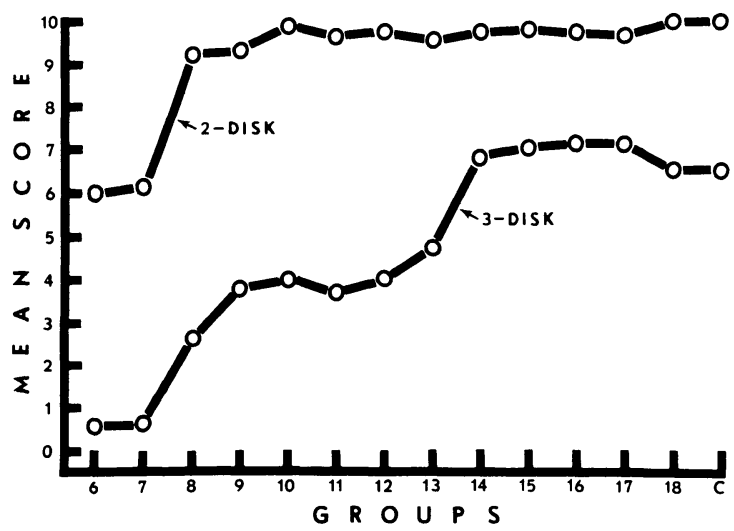

Figure 1. Performance of subject groups on the two-disk and three-disk Tower of Hanoi problem. 
that blocking the goal peg is a general hindrance to the problem solving plans of the maturationally young.

\section{REFERENCE NOTE}

1. Klahr, D. Problem solving and planning by preschool children Paper presented at the biennial meeting of the Society for Research in Child Development, San Francisco, March 1979.

\section{REFERENCES}

Byrnes, M. M., \& Spitz, H. H. Performance of retarded adolescents and nonretarded children on the Tower of Hanoi problem. American Journal of Mental Deficiency, 1977, 81, 561-569.

Соок, T. W. Amount of material and difficulty of problem solving. Il. The disk transfer problem. Journal of Experimental Psychology, 1937, 20, 288-296.
Ewert, P. H., \& Lambert, J. F. Part II: The effect of verbal instructions upon the formation of a concept. Journal of General Psychology, 1932, 6, 400-413.

Gagné, R. M., \& Smith, E. D., JR. A study of the effects of verbalization on problem solving. Journal of Experimental Psychology, 1962, 63, 12-18.

KIRK, R. E. Experimental design: Procedures for the behavioral sciences. Belmont, Calif: Brooks/Cole, 1968.

KLAHR, D. Goal formation, planning, and learning by pre-school problem solvers. In R. S. Siegler (Ed.), Children's thinking: What develops? Hillsdale, N.J: Erlbaum, 1978.

Piaget, J. [The grasp of consciousness: Action and concept in the young child] (S. Wedgwood, trans.). Cambridge, Mass: Harvard University Press, 1976. (Originally published, 1974.) Simon, H. A. The functional equivalence of problem solving skills. Cognitive Psychology, 1975, 7, 268-288.

(Received for publication August 1, 1979.) 